\title{
Job Seekers' Perceptions about the PNet Website as an E-Recruitment Tool within South Africa
}

\author{
Prof. B. Grobler \\ University of Johannesburg \\ bennieg@uj.ac.za \\ Dr. P. Joubert \\ Vaal University of Technology \\ pierrej@vut.ac.za \\ Mr K. Lesuthu \\ Vaal University of Technology \\ klesuthu@ymail.com
}

\section{Doi:10.5901/mjss.2014.v5n7p530}

Abstract

The primary objective of the study was to evaluate job seekers' perceptions about the PNet website as an e-recruitment tool in South Africa. There have been many variation regarding sophistication, types and success of recruitment websites and, research has lagged behind on the subject of these rapid changes in practice. On one hand companies continue to make huge investments in these e-applications whereas they have limited knowledge regarding evaluation of success of these applications. On the other hand, customers whom these systems are designed for, vary considerably on their ability to use them. A cros-sectional survey was conducted using a structured questionnaire to collect data form the sample. The purposive sampling of the job seekers who use the PNet website to search for jobs was undertaken $(n=717)$. There was a statistically significant association between the perceptions of job seekers about the PNet website as and e-recruitment tool and their level of educational qualifications, as well as with gender of respondents. Job seekers with higher educational qualification were found to have less positive perceptions. Male respondents were found to be more positive than female respondents. The highly qualified job seekers are more costly to recruit, thus, they represent a more lucrative market for recruiters and PNet is likely to lose this segment of job seekers. More information about this segment should be gathered in order to find ways to attract this lucrative market.

\section{Introduction and Background to the Study}

As the Internet grew in popularity from mid 1990s towards the end of the 20th century, organisations began to sift ways to exploit the new technology to their benefit (Reynolds \& Weiner 2009). According to Reynolds and Weiner (2009), recruitment is one of the first business processes to adopt the Internet within business functions, while other organisations emerged as service providers of the Internet recruitment, undertaking the full function as their core business (Tong 2009). The emergence of this technology came along with many altered names such as e-recruiting, web-based recruiting, online recruitment, web recruitment, recruiting on the Internet and e-cruiting, all of which can be used as search terms about the topic on the Internet (Wolfswinkel, Furtmueller \& Wilderom 2010).

According to Lee (2005), e-recruitment started with a function of only posting the vacancy information on the website with instructions on how candidates should apply (for example; fax number or a postal address where candidates should send their résumés). Since the introduction of e-recruitment, it has evolved and multiplied into different types such as hybrid recruiting service providers and e-recruiting consortiums (Lee 2007), as well as on the Internet communities like, "MySpace, Facebook, Twitter, LinkedIn" (Lee 2011:231). Such environments may vary in sophistication from relatively simple bulletin boards that provide basic job descriptions with little or no opportunity to the applicant, to highly sophisticated sources that allow applicants to complete job application and even perform job interviews.

People tend to differ with regard to the level of comfort they experience when using more advanced ways to interact with persons or organisations, as a result, they may hold different dispositions towards e-recruitment (Van 
Birgelen, Wertzels and Van Dolen 2008). More importantly, little is known about applicants' reactions to e-recruitment because research has only begun to explore this issue (Thompson, Branddy \& Wuensch 2008). The acceptance and use of e-recruitment systems will be influenced by the degree to which applicants perceive they will facilitate the attainment of their job and career-related goals (Stone, Stone-Romero \& Lukaszewski 2006). Therefore, there is a need for a better understanding of how job applicants psychologically engage with the organisation through the corporate website (Van Birgelen et al. 2008).

From a consumer behaviour perspective, the digital media are affecting the information environment and consumer behaviours in an extraordinary way due to unique characteristics of the Internet, such as the speed of access, scope of access, provision of interactive assistance, and flexibility in representing information (Kima, Lehtob \& Morrison 2007:246).

On one hand, Constantinides (2004) notes that more recent anecdotal and empirical evidence indicate that many online firms still do not completely understand the needs and behaviour of the online consumers, while many of them continue to struggle with how to effectively market and sell their products online. On the other hand, previous research has shown that people vary widely in their ability to find and retrieve information in flexibly structured information environments (Kima et al. 2007).

Despite the knowledge gap between service providers and customers, companies continue to make huge investments in e-business applications but are pressurised to evaluate the success of their e-business systems, as a result, researchers have turned their attention to developing, testing, and applying e-business success measures (Lee \& Kozar 2006). Besides that, recent reviews of applicant reactions and web-based recruitment procedures, research into applicant reactions to recruitment websites remains notably sparse (Sylva \& Mol 2009), hence this study is focused on job seekers' perceptions about one of the recruitment websites in South Africa.

Maurer \& Liu (2007) define e-recruitment as, the online environment that allows companies and job applicants to interact with each other. For the purpose of this study, the type of website used for this study is a General-purpose job boards website. General-purpose job boards are privately-owned websites that provide job seekers and employers with e-recruitment services (Tong \& Sivanand 2005). Most of these websites are designed to allow employers and job seekers to interact through (a) posting of vacancies by employers, (b) posting of résumé profiles by job seekers, and (c) searching for résumés by employers or vacancies by job seekers. A specific criterion (for example location, skill level, vacancies' category, qualifications) can be used to limit the search output by both job seekers and employers (Liu \& Chen 2009). However, these functions are dependent on the sophistication of the e-recruiting system.

\section{Literature Review}

\subsection{Technology acceptance model (TAM)}

In order to evaluate these perceptions, the study followed the technology acceptance model originally developed by Davis (1986) as alluded to by many authors (Legris, Ingham \& Collerette 2003; Yousafzai, Foxall \& Pallister 2007; Lin \& Chou 2009; Hsiao \& Yang 2011). According to Davis (1993), the TAM provides an informative representation of how functions and interface characteristics of a system affect acceptance and usage of a system. The TAM depicts how such design choices (functions and interface characteristics) leads to actual system usage through TAM motivational variables, which are attitude toward using, perceived usefulness, and perceived ease of use (Davis, 1993), as shown in Figure 1.

Figure 1. Technology acceptance model

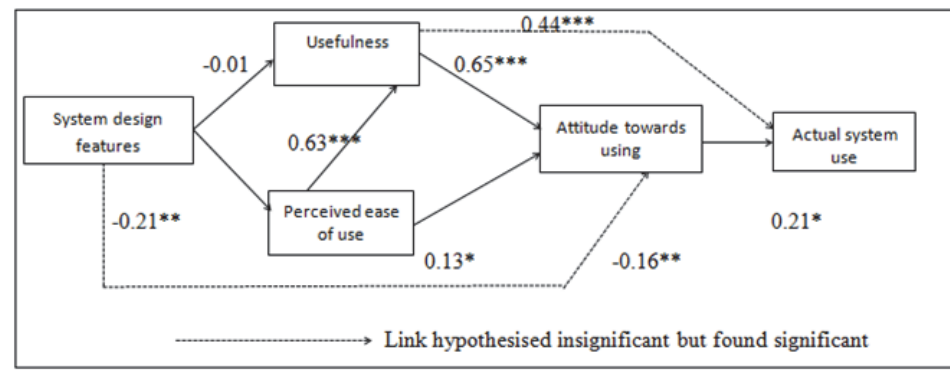

Source: Davis (1993) 
Davis (1993) is of view that individual's affect towards using the system is jointly determined by both intrinsic and extrinsic rewards, and not only on extrinsic rewards, as the model initially indicated. Therefore, more research is needed to address the relative roles of intrinsic and extrinsic motivation in user acceptance as well as additional variables within TAM, such as system familiarity or experience, top management support, user involvement, task characteristics, system layout, and so on (Davis 1993). Thus, TAM is subject to alterations to suit different information system studies. For the purpose of the e-recruitment context, the researchers added the motivational variables to the pre-existing motivational TAM variables that are known to influence decisions of the job seekers to apply or respond to an e-recruitment advertisement. These motivational variables include attraction to the website, quality of the website service, information relevancy, timeliness of information, information accuracy, information relevancy and intentions to apply. Subsequently, the aforementioned motivational variables are discussed.

\subsection{Attraction to the website}

Lyons and Marler (2011), state that research shows that a website's aesthetic features and employment content information are positively associated with organisational attraction (the firm or company behind the website). Therefore, favourable perceptions of both website attributes and employment content information should invoke positive beliefs about the organisation. Schreurs and Syed (2011) note that, attractiveness of the website influences the job seeker's job choice as it is associated with characteristics of the recruiter.

Advertising of jobs is a major recruitment function (Lang, Laumer, Maier \& Eckhardt 2011). Zusman and Landis (2002) connote that, as with consumer advertisements, job advertisements should attract attention through website characteristics, hold interest through information relevant to the viewer, gain acceptance depending on information credibility, establish preference over other websites, and motivate action by allowing for a search and application for positions. In line with Williamson, Lepak and King (2003), the first critical step in employee recruitment is to attract individuals to apply for positions, as organisations that attract more applicants that are qualified will have a larger pool from which to choose. Nevertheless, if individuals do not apply, they cannot be influenced by subsequent recruitment activities (Williamson et al. 2003).

Zusman and Landis (2002) allude that the website's characteristics that differentiates attractive websites from less attractive ones are technical format, textual format, layout, and colouring. Additionally, providing tools that ease the navigation of the site and allow direct access to the information that the viewer desires to see, increases attractiveness of the website (Zusman \& Landis 2002). This attractiveness can facilitate capturing of attention of a potential applicant, ignite interest and direct the applicant's action (Zusman \& Landis 2002). Thus, attraction will play a major role on job seekers' preference on websites that equally meet his or her needs.

According to Celani and Singh (2011), the extent to which applicants identify with the recruiting organisation positively influences applicant attraction outcomes such as job pursuit intentions, job-organisation attraction, and job acceptance intentions. The utmost importance of applicant attraction is that suitably qualified applicants are likely to remain in the selection process (Hu, Su \& Chen 2007), that is, after the recruiter has filled the vacancy, qualified candidates who were not chosen to fill the vacancy, may remain available for recruitment for future opportunities that may arise.

\subsection{The ease of use of the website}

Davis (1989:320) explains perceived ease of use as "the degree to which a person believes that using a particular system would be free of effort." He further explains the definition of ease as, freedom from difficulty or great effort, while effort is a finite resource that a person may allocate to the various activities for which he or she is responsible (Davis 1989:320). According to Casalo Flavia'n. and Guinali'u (2008:326), website usability is defined as, "a quality attribute that assesses how easy user interfaces are to use."

Briefly, Casalo et al. (2008) state that the concept of usability considers the following factors, namely the ease of understanding the structure of a website, its functions, interface and the contents that can be observed by the user; its simplicity of use in its initial stages; the speed at which the users can find what they are looking for; the perceived ease of site navigation in terms of time required and action necessary in order to obtain the desired results; and the ability of the users to control what they are doing and where they are at any given moment. 


\subsection{Perceived usefulness of the website}

Davis (1989:320) clarifies perceived usefulness as "the degree to which a person believes that using a particular system would enhance his or her job performance." Perceived ease of use (EU) and perceived usefulness (PU) are two primary predictors in the technology acceptance model (King \& He 2006).

\subsection{Attitude towards the website}

Teoa, Oha, Liua and Weib (2003:284) define an attitude as, "a predisposition to respond in a particular way towards a specified class of objects." Furthermore, the literature indicates that a positive attitude towards information systems will increase the actual use of the system (Teoa et al. 2003). Although several authors recommend the elimination of attitudes to increase the parsimony to TAM models, other researchers have identified attitudes towards usage as a major determinant of the behavioural intention to use a system, including studies focused on Internet applications (Egea \& González 2011).

"In general, object-based attitudes (attitudes about a system) can also be predictive of a behavioural disposition by influencing the way in which information about it is perceived and judged" (Wixom \& Todd 2005:90). Wixom and Todd (2005:90) also state that, "Beliefs about using the system to accomplish a particular task will be shaped, in part, by the attitude toward the system itself. Indirectly these beliefs will shape the attitude toward use and eventual usage behaviour." In addition, Liaw (2007:400) indicates, "no matter how advanced or capable the technology is, its effective implementation depends upon users having a positive attitude toward it."

Besides that attitude plays a major role in brand preference among consumers. According to Kardes Cline and Cronley (2008), when consumers are faced with a choice between competing products, they hardly recall each of the products' attributes that motivate their choices; instead, attitudes are readily in place to make a choice in most cases.

\subsection{Quality of the website service}

Kim and Stoel (2004) note that the dimensions of website quality would be expected to differ according to the function of the site. For the purposes of this study, website quality is defined as "the performance of the system in delivering information" (Lee \& Kozar 2006:1389). It is an overall judgment, or evaluative component of attitude relating to the superiority of a service (Tong et al. 2005). Lee and Kozar (2006) further indicate that according to the e-business context, website system quality has been known to have a significant effect on online customer satisfaction. Furthermore, a number of studies using path analysis found that information quality and system quality were significant determinants of overall user satisfaction (Livari 2005).

Website quality factors also appear to have an impact on users' acceptance, as they are a means of influencing user beliefs and their behavioural intentions. In addition, they are within the control of the company. Hernández, Jiménez and Martín (2009:363) state, "the quality of the website affects the users' impression of the company because it is the portal through which the company's transactions are conducted." According to Tong et al. (2005), if job seekers are unhappy with the service provided by the recruitment website, they may look for other websites that fulfil their expectations for service quality. If this continues to happen, the websites with low service quality for the job seekers may experience a decrease in the number of active job seekers (Tong et al. 2005:689).

\subsection{Information relevancy}

In addition to perceived usefulness, user attitudes toward using the Internet and perceived performance (Shih 2004) connote relevance as a strong determinant of perceived ease of use. Relevance includes information depth, scope and completeness applicable to the user (Lee \& Kozar 2006:1388). Information relevance assures that the information content provided within web pages is in line with users' needs and interests (Kim, Kishore \& Sanders 2005:79).

There is a strong relationship between users' opinions about the relevance of the system and their own goals and aspirations, as these opinions will influence how they value the system as well as its success (Seddon \& Kiew 1996). For example, if what the system does is not important to the user, there seems to be a little chance that the user will perceive the system as useful, no matter how well designed it is, or how easy it is to use (Seddon \& Kiew 1996). 


\subsection{The timeliness of information}

In the context of this study, "timeliness represents user's perception of the degree to which information is up-to date" (Wixom \& Todd 2005:91). Boritz (2005:265) states that, "it must be accepted that absolute completeness and accuracy are impossible or impractical to achieve." For example, an employment position that has already been filled may still be found available on the recruiting website for potential candidates to apply for it. Information currency/timeliness is affected by the difference of information on the website about the product and its actual condition (as well as by information processing delays), as the world changes over time with a proportionate impact on information accuracy (Boritz 2005).

Boritz (2005) further endorses that, as time is continuous, completeness and accuracy must be understood in a context that defines acceptable limits for information timeliness, hence its accuracy. Thus, if information on the website has scheduled standardised updating periods, information that was not updated accordingly is deemed as not up-to date.

\subsection{Information accuracy}

Batini, Cappiello, Francalanci and Maurino (2009) define accuracy as the extent to which information is correct, reliable and certified. According to Wixom and Todd (2005), accuracy represents the users' perception that the information is correct.

Data quality approaches have primarily involved the content of the information (such as its relevance, accuracy, and completeness) (Kim et al. 2005). Furthermore, Kim et al. (2005) indicate that the content dimension consists of three quality constructs, which are information accuracy, information relevance, and information completeness, as it commonly is agreed that retrieved information should be accurate, relevant, and complete in order to add value to the task for which it is retrieved.

\subsection{Intentions to apply}

"The behavioural intention construct refers to the degree to which a person has formulated a conscious decision to perform or not perform a particular behaviour" (Hasan \& Ahmed 2007:3031). According to Hasan and Ahmed (2007), the technology acceptance model postulates that the acceptance of information systems is determined by behavioural intention (BI) to use a system. Behavioural intention is in turn jointly determined by beliefs about the ease of use (PEOU) and perceived usefulness (PU) of a system.

Casaló, Flavián and Guinalíu (2010) state that, in technology acceptance contexts, intentions often serve to measure consumer behaviour. Behavioural intentions imply that a person is likely to behave in a specified way, for example to apply for a job that is advertised over the Internet. This is so because real behaviour and behavioural intentions are highly correlated (Casaló et al. 2010:899).

\section{Research Methodology}

A cross-sectional survey design was conducted using a structured questionnaire to collect data the sample. This method was found suitable for the study as the objective was to make statistical inferences about the target population. The cross-sectional survey enables collection of data form high population sample within a shorter time frame (Churchill \& lacobucci 2005).

\subsection{Research sample}

The purposive sampling of job seekers who use the PNet website to search for jobs was undertaken $(n=717)$. Purposive sampling is a type of non-probability sampling which involves deliberate choosing of units of analysis that have similar attributes to that of the total population (Welman, Kruger \& Mitchell 2005:51).

\subsection{Method of data collection}

The primary data was obtained from the samples by means of a questionnaire. The questionnaire was distributed using the SogoSurvey online tools. These tools assisted with conversion of the original questionnaire into a copy that enables respondents to complete the questionnaire online. A banner, linked to the questionnaire, was posted on the PNet website 
to invite PNet users to participate in the survey. This banner was only accessible to those who logged on to the website, in order to restrict participation to the registered PNet users.

\subsection{Measuring instrument}

The questionnaire was built through the adoption of relevant constructs from Liaw and Huang (2003) and Van Birgelen et al. (2008). It consisted of closed-ended or structured questions. The questionnaire was divided into four sections, namely A, B, C and D. Section A contained demographic questions; this section included demographics regarding age, gender, experience using recruitment websites, educational levels and the like, which may have an effect on users' perceptions. Section B consisted of factors that are known to influence jobseekers' response to a job advertisement (Zusman \& Landis 2002; Van Birgelen et al. 2008; Breaugh 2008). While Section C entailed technology acceptance factors that influence individuals to accept and predict usage of a technological products or services (Davis 1989; Lee \& Kozar 2006). Lastly, Section D contained questions that measure intentions of respondents' future use of the website. From section $B$ to $D$, all responses were measured on a six point Likert-type scale ranging from 1=strongly disagree and $6=$ strongly agree with the given statements.

\subsection{Statistical analysis}

The Statistical Package for Social Sciences (SPSS version 20.0 for Windows) was used to analyse the data. The sample will first be described using descriptive statistics to indicate the representivity of the sample to the population, and then inferential statistical procedures were utilised to analyse the data further.

\section{Results and Discussion}

Table 1 indicates sample's demographic characteristics.

Table 1. Demographic characteristics of the sample

\begin{tabular}{|l|c|c|}
\hline Gender: & Frequency & Percentage \\
Male & 368 & 51.3 \\
Female & 349 & 48.7 \\
Total & 717 & 100 \\
\hline Age category: & & \\
18 - 24 years & 120 & 16.7 \\
25 - 30 years & 256 & 35.7 \\
31 - 35 years & 126 & 17.6 \\
36 and above & 215 & 30.0 \\
Total & 717 & 100 \\
\hline Highest level of education: & & \\
High School education (Grade 12) & 201 & 29.1 \\
College education (N6) or diploma & 151 & 21.9 \\
Undergraduate at university & 60 & 8.7 \\
University diploma & 78 & 11.3 \\
University degree & 119 & 17.2 \\
Postgraduate degree (honors, Masters, etc) & 81 & 11.7 \\
Total & 690 & 100 \\
\hline Level of experience regarding job search using websites: & & \\
0 - 1 Years & 180 & 25.1 \\
2 - 3 Years & 215 & 30.0 \\
4 - Years & 138 & 19.2 \\
6 Years and above & 184 & 25.7 \\
Total & 717 & 100 \\
\hline Frequency of job search using websites & & \\
Daily & 293 & 41.3 \\
Every 2- 3 days & 176 & 24.8 \\
Weekly & 164 & 23.1 \\
Monthly & 76 & 10.7 \\
Total & 709 & 100 \\
\hline
\end{tabular}


Having indicated the summary of demographic characteristics of the sample, below is the results showing reliability of theoretical constructs used in the questionnaire to scale data.

\subsection{Theoretical factor results}

The questionnaire contained nine theoretical factors or constructs and each one of the constructs had from three to four items that attempted to measure the construct. Table 2 provides a summary of the reliability of the theoretical constructs as determined by using the Cronbach Alpha reliability coefficient present in the SPSS 20.0 package (Norusis 2009:431).

Table 2. Reliability of the nine theoretical constructs of the PNet website

\begin{tabular}{|l|c|c|}
\hline \multicolumn{1}{|c|}{ Theoretical construct } & Number of items & Cronbach reliability \\
\hline Q9.Information relevancy & 4 (C and D inverted) & 0.72 \\
\hline Q10.Information accuracy & 4 (C and D inverted) & 0.74 \\
\hline Q11.Information timeliness & 3 & 0.85 \\
\hline Q12.Attraction to the website & 5 & 0.93 \\
\hline Q13. Attitude towards & 5 & 0.92 \\
\hline Q14. Perceived usefulness & 3 & 0.93 \\
\hline Q15. Ease of use & 4 (D inverted and removed) & 0.90 \\
\hline Q16. Quality of service & 3 & 0.91 \\
\hline Q17. Intention to apply & 2 (C and D inverted- removed) & 0.85 \\
\hline
\end{tabular}

Each of the nine theoretical factors were tested for normality of distributions but all were negatively skew, and hence nonparametric procedures need to be used to test these theoretical factors and the independent groups. The factorial procedure method indicated that the nine first-order factors could be further reduced to just one factor which was named, 'the perceptions of job seekers about the PNet website as an e-recruitment tool (FB2.0)'. The nine first-order factors and the names allocated are given in Table 2. It could be said that the nine theoretical factors are the underlying subdimensions on which the perceptions of job seekers about the PNet website as an e-recruitment tool are built. Thus, the question that now arises is on which of these nine sub-dimensions do respondents differ. Below is the results whereby statistically significant differences were found within the respondents.

\subsubsection{Comparison between the gender groups for significant differences with respect to the nine sub-dimensions of the perceptions of job seekers about the PNet website}

However, all of the factors were negatively skew, as respondents tended to agree with the items posed. The five firstorder factors were subjected to another or successive factor analytic procedure. The KMO of 0.85 and Bartlett's sphericity of $p<0.0005$ indicated that such a procedure would be plausible. Among all groupings, it was only in gender where independent groups were found hence the t-test was used to determine significant differences in gender as shown in table 3 below.

Table 3. Significance of differences between the two gender groups with respect to the perceptions of job seekers about the PNet website as an e-recruitment tool

\begin{tabular}{|c|c|c|c|}
\hline Item & Group & Mean score & t-test (p-value) \\
\hline \multirow{2}{*}{$\begin{array}{l}\text { The perceptions of job seekers about the PNet website as } \\
\text { an e-recruitment tool (FB2.0) }\end{array}$} & Male & 4.77 & \multirow{2}{*}{$0.001^{* *}$} \\
\hline & Female & 4.64 & \\
\hline
\end{tabular}

Information timeliness: Male respondents had a statistically significantly higher mean rank score (MRS $=370.5)$ than females had (MRS=339.65). The data with respect to the timeliness sub-dimension was $U=57495.50 ; Z=-2.06 ; p=0.04$; $r=0.08$. Male respondents thus agreed statistically significantly more strongly with the timeliness of the information on the PNet website than female respondents did.

Attitude towards the PNet website: Male respondents agreed more strongly (MRS=372.24) with the attitude factor than female respondents did (MRS=335.84). The appropriate data was $U=56853.50 ; Z=-2.259 ; p=0.02 ; r=0.09$. In the 
sample, tested males had a statistically significantly more positive attitude towards the PNet website than females did.

Usefulness of the PNet website: The mean rank score of males was 374.08 compared to the females 335.84 .

Hence, male respondents agreed to a statistically significantly greater extent with the usefulness of the PNet website than females did ( $U=56179.50 ; Z=-2.59 ; p=0.01 ; r=0.10)$.

Quality of the website: Again the male respondents (MRS=372.00) agreed to a statistically significantly greater extent with the quality sub-dimension than female respondents (MRS=338.04) did. The two gender groups also differed statistically significantly in their mean ranked scores $(U=56940.0 ; Z=-2.302 ; p=0.021 ; r=0.09)$. Male respondents were thus more positive about the quality of the PNet website than female respondents were.

\subsubsection{Comparison between the six qualification groups for significant differences with respect to the nine sub-dimensions of the perceptions of job seekers about the PNet website}

When comparing three or more independent groups with one another, the Kruskal-Wallis test is the non-parametric counterpart of the ANOVA test (Field 2009:558). A comparison between the nine theoretical sub-dimensions against the six-qualification groups will be possible using this test. Only those sub-dimensions where statistically significant differences were found are discussed.

Table 4. Significance of differences between the various qualification groups with respect to FB2.0

\begin{tabular}{|c|c|c|c|c|c|c|c|c|c|c|}
\hline Item & Group & Mean & $\begin{array}{l}\text { ANOVA } \\
\text { (p-value) }\end{array}$ & \multicolumn{7}{|c|}{$\begin{array}{l}\text { Pair-wise comparisons (Scheffe or } \\
\text { Dunnett T3 }\end{array}$} \\
\hline \multirow{7}{*}{$\begin{array}{l}\text { The perceptions of job seekers about the } \\
\text { PNet website as an e-recruitment tool } \\
\text { (FB2.0) }\end{array}$} & & & \multirow{7}{*}{$0.002^{\star *}$} & & $A$ & B & C & D & $E$ & $F$ \\
\hline & A & 4.76 & & A & 7 & - & - & - & - & ** \\
\hline & B & 4.76 & & B & - & 1 & - & - & - & ** \\
\hline & C & 4.71 & & C & - & - & 1 & - & - & - \\
\hline & D & 4.66 & & D & - & - & - & $\angle$ & - & - \\
\hline & $E$ & 4.72 & & $\mathrm{E}$ & - & - & - & - & 1 & - \\
\hline & $F$ & 4.49 & & $F$ & ** & ** & - & - & - & 7 \\
\hline
\end{tabular}

$\mathrm{A}=$ Grade 12/undergraduate at college

$\mathrm{B}=\mathrm{N} 6$ or diploma

$\mathrm{C}=$ Undergraduate at university

$\mathrm{D}=$ University diploma

$\mathrm{E}=$ Bachelors degree

$\mathrm{F}=$ Postgraduate qualification.

$* *=$ Statistically significant at the one percent level $(p<0.005)$

$*=$ Statistically significant at the five percent level $(p>0.01$ but $p<0.05)$

Timeliness of PNet website: The Kruskal-Wallis test $(\mathrm{H})$ indicated that the timeliness of information differed statistically significantly when all six qualification groups are considered together $\left[X^{2}(5)=14.50 ; p=0.013\right]$. As there are six qualification groups, the comparisons were made selectively as the Bonferroni correction means that the 0.05 level must be divided by the number of comparisons made. Comparisons in this study were made between groups one with six and two with six, based on the analysis in Table 4. Hence, the significant $p$ value was 0.025 .

Group 1 was the grade 12/undergraduate at college group who had a mean rank of 152.39 compared to Group 6 who were postgraduates (MR=114.48). These two groups differed statistically significantly regarding the timeliness subdimension $(U=5952.00 ; p=0.000 ; Z=-3.66 ; r=0.22)$. Group 2, with an N6 or diploma, also differed statistically significantly from Group 6 respondents regarding the timeliness factor $(U=4794.00 ; p=0.000 ; Z=0.005 ; r=0.18)$. It seems reasonable to find a statistically significant difference between these groups regarding the timeliness sub-dimension, as the more qualified the person is, the higher the skills possessed. These skills may include assessment or interpretation of information at a different level, as well as attentiveness to details. Thus, better-qualified respondents can quickly realise if they come across the new or old information on the website.

Attraction of the website: With respect to the sub-dimension attraction to the website the Kruskal-Wallis test indicated that there was a significant difference between the various qualification groups $\left[X^{2}(5)=11.50 ; p=0.04\right]$. When doing the post-hoc tests the Mann Whitney $U$ test was utilised. A Group 1 comparison with Group 6 indicated that the grade 12/undergraduate at college group differed statistically significantly from the postgraduate group (U=6301.000; Z=3.06; $p=0.002 ; r=0.18)$. Group 2 with an N6 or diploma qualification also differed statistically significantly from the 
postgraduate group ( $U=4794.00 ; Z=-2.78 ; p=0.019 ; r=0.17)$. Therefore, the significant $p$-value of 0.019 is met, as the probability value is less than the required Bonferroni correction of 0.025 .

This difference could be ascribed to limited information about the job vacancy posted on the PNet website. As mentioned earlier, PNet as a general-purpose board allows recruiters to post limited information about the employer and the job (Lee 2005:60). It is thus possible that the attraction of well-qualified candidates to the employment website is mediated by the limited amount of information that is communicated to them (Zusman \& Landis 2002: 289). Hence, highly qualified candidates, such as those with a postgraduate qualification, find the attractiveness to the website to be significantly less than respondents with lower qualifications find the attractiveness.

Attitude towards the website: The various qualification groups also differed from one another regarding their attitudes towards the PNet website $\left[X^{2}(5)=19.07 ; p=0.002\right]$. It was again Group 6, the postgraduates, who differed from Groups 1 and 2 regarding the attitude towards the website. The postgraduates had a statistically significantly lower mean ranked score than did the grade 12/undergraduate at college and N6 or diploma group. For the Group 1/Group 6 comparison, the appropriate non-parametric values were $(U=5685.00 ; Z=-4.005 ; p=0.000 ; r=0.24)$. For the Group $2 /$ Group 6 comparison, the values were $(U=4472.00 ; Z=-3.41 ; p=0.001 ; r=0.20)$. Concerning attitude, it is understood that it was an expected finding that is consistent with other important attributes of the website. According to Kardes et al. (2008:151), the extent to which a product satisfactorily meets one's expectations or needs would determine his or her attitude. In addition, the attributes of a product shape the attitude of the consumer; hence, consumers mostly already have attitudes in place before making a decision to purchase.

Ease of use of the PNet website: The Kruskal-Wallis test indicated that the various qualification groups differed statistically significantly from one another when considering all six groups together $\left[X^{2}(5)=25.72 ; p=0.000\right]$. The MannWhitney U-Test indicated that the lowest qualification groups, with grade 12 or undergraduates at college, differed statistically significantly from the postgraduate group ( $U=5387.00 ; Z=-4.543 ; p=0.000 ; r=0.27$ ). Group 2 also differed statistically significantly from the postgraduate group and the Mann-Whitney values were $(U=4060.00 ; Z=-4.297$; $p=0.000 ; r=0.26)$.

The important factors that influence perceived ease of use (PEOU) are familiarity and self-efficacy (Davis 1989:321; Davis \& Venkatesh 1996:20). It may be worth exploring if experience regarding usage of the website can be related to PEOU. However, as most South Africans access the Internet at workplaces or schools (Brown, Letsididi \& Nazeer 2009:1), and seek employment at different levels of their qualifications, it becomes reasonable to find differences among qualification groups, as time spent to familiarise themselves with the website is likely to vary.

Quality of the PNet website service: The Kruskal-Wallis test results were $\left[X^{2}(5)=16.90 ; p=0.005\right]$. The MannWhitney U-test for pair-wise comparison again indicated that Group 1 and Group 2 differed from Group 6 regarding the quality of the website service with the postgraduate group agreeing less strongly with the sub-dimension of quality service. For the Group 1/Group 6 comparison the values were $(U=5984.00 ; Z=-3.64 ; p=0.000 ; r=0.22)$. The Group 2/Group 6 comparison gave similar results $(U=4362.00 ; Z=-3.73 ; p=0.000 ; r=0.22)$. The lowest qualified groups thus agreed more strongly about the quality of the website service than did the postgraduate group. This finding was similar throughout this research. As quality of service is an overall individuals' judgement on how good or bad the service is (Tong et al. 2005:699) this finding is compatible with sub-dimensions that were measured earlier, where statistically significant differences between Group 6 and Group 1 or Group 2 were also found.

Furthermore, the researcher wished to determine which of the nine theoretical factors were the best predictors of the perceptions' of job seekers regarding the use of the PNet website as a recruitment tool (FB2.0). Multiple regression analysis was used to assist in this regard.

\subsubsection{Using multiple regression to determine which theoretical factors are the best predictors of FB2.0 as outcome variable}

Making use of websites for job seekers in the South African context is a relatively new concept with respect to the other methods that companies use in recruiting employees. It would thus be useful to know which of the predictors used in the questionnaire were found to be the most important with respect to the PNet website. The outcome variable (FB2.0) can be found by using the multiple regression equation,

$Y_{F B 2.0}=\left(b_{0}+b_{9} X_{9}+b_{10} X_{10}+\ldots \ldots \ldots \ldots b_{17} X_{17}\right)$, where $\mathrm{Y}$ is the outcome variable, $\mathrm{b}_{9}$ is the coefficient of the ninth predictor $\left(X_{9}\right)$ and so on (Field, 2009:210).

The researchers also added all nine theoretical factors as predictors, as it was uncertain which of these factors were significant predictors of the PNet website as an e-recruitment tool in the South African context. Table 3 provides the 
parameters of the model produced by SPSS 20.0 .

Table 5. The regression model with the theoretical factors as predictors of PNet as an e-recruitment tool

\begin{tabular}{|c|c|c|c|c|c|c|c|c|}
\hline & & & & & & Change Statisti & & \\
\hline Model & $\mathrm{R}$ & & Adjusted R Square & Std. Error of the Estimate & R Square Chang & e F Change df1 df2 & Sig. F Change & Watson \\
\hline 1 & $.968 \mathrm{a}$ & 938 & 937 & .13086 & .938 & \begin{tabular}{|l|l|l|}
1170.828 & 9 & 700 \\
\end{tabular} & .000 & 1.943 \\
\hline
\end{tabular}

- a. Predictors: (Constant), Theoretical factor on intention to use, Theoretical factor on information relevancy, Theoretical factor on information timeliness, Theoretical factor on ease of use of the website(D Removed), Theoretical factor on information accuracy, Theoretical factor on attitude towards the website, Theoretical factor on attraction to the website, Theoretical factor on quality of website, Theoretical factor on perceived usefulness of the website

- b. Dependent Variable: Mean score of FB2.0

The data in the model indicate that the theoretical factors explain $93.8 \%$ of the variance present in the outcome variable. Furthermore, it indicates that the change in the F-ratio is statistically significant $(p<0.0005)$. The Durbin-Watson value is close to two, indicating that the errors in the regression are independent. The ANOVA model indicated that the model was a significant fit of the data overall $[F(9,700)=1170.83 ; p=0.000]$

In Table 5, the b-values in the multiple regression equation, shown below, are the regression coefficients (indicated as B values by SPSS in the second column in Table 6). In other words they provide the individual contributions of each theoretical factor to the outcome variable.

( $P$ Net as recruitment $=b_{0}+b_{9}$ intention to use $+b_{10}$ information relevancy $+\ldots b_{17}$ usefulness)

$[$ PNet $=1.296+(0.056$ Intention to used $)+(-0.091$ Information relevancy $+\ldots)]$

All nine of the theoretical factors were significant predictors of the outcome variable. The b-values were all positive, with the exception of information relevancy and accuracy, which were negative. The positive b-values indicate that as those predictors increased so does the outcome, namely the perceptions of job seekers regarding PNet as an erecruitment tool (FB2.0). With respect to information accuracy and relevancy it needs to be remembered that the scales of the items were reversed and hence these two are more difficult to interpret. If the scale was reversed then the interpretation would still be a positive one with respect to the outcome variable. The standardised Beta value $(\beta)$ indicates the importance of each predictor in the outcome variable. Thus, the attitude towards the website (.285) was the most important predictor, followed by information timeliness (.231), then attraction to the website (.182), usefulness of the website (.180), and so on.

Table 6. The coefficients of the regression model produced by SPSS 20.0

\begin{tabular}{|c|c|c|c|c|c|}
\hline \multirow{2}{*}{ Model } & \multicolumn{2}{|c|}{ Unstandardised Coefficients } & \multirow{2}{*}{\begin{tabular}{|c|} 
Standardised Coefficients \\
Beta
\end{tabular}} & \multirow{2}{*}{$\mathrm{t}$} & \multirow{2}{*}{ Sig. } \\
\hline & $B$ & Std. Error & & & \\
\hline (Constant) & 1.296 & .044 & & 29.272 & .000 \\
\hline Theoretical factor on information relevancy & -.091 & .008 & -.147 & -11.314 & .000 \\
\hline Theoretical factor on information accuracy & -.093 & .009 & -.147 & -10.932 & .000 \\
\hline Theoretical factor on information timeliness & .145 & .008 & .231 & 17.744 & .000 \\
\hline Theoretical factor on attraction to the website & .124 & .011 & .182 & 10.813 & .000 \\
\hline 1 Theoretical factor on attitude towards the website & .173 & .010 & .285 & 17.769 & .000 \\
\hline Theoretical factor on perceived usefulness of the website & .120 & .012 & .180 & 9.865 & .000 \\
\hline Theoretical factor on ease of use of the website(D Removed) & .118 & .012 & .170 & 10.094 & .000 \\
\hline Theoretical factor on quality of website & .105 & .011 & .167 & 9.558 & .000 \\
\hline Theoretical factor on intention to use & .056 & .010 & .074 & 5.482 & .000 \\
\hline
\end{tabular}

\subsection{Empirical findings}

The job seekers' perceptions were found to be positive overall. However, Male respondents were found to be more positive than female respondents regarding attitude towards the website, the website's timeliness of the information, the quality and ease of use of the website. Respondents with higher educational qualifications were found to have less positive perceptions regarding the timeliness, attraction to, attitude towards, ease of use and quality of the PNet website, 
than respondents with lower educational qualifications.

There was a statistically significant association between the perceptions of job seekers about the PNet website as an e-recruitment tool and their educational qualifications, as well as with gender of the respondents. Using the standardised Beta value ( $\beta$ ) the findings revealed that the attitude towards the website $(.285)$ was the most important predictor, followed by information timeliness (.231), then attraction to the website (.182), usefulness of the website (.180) ease of use of the website (.170) and quality of website (.167).

\section{Concluding Remarks}

Despite impressive results that showed that PNet customers (the job seekers) were satisfied with the overall performance or service delivered by the website, there are some theoretical and empirical findings that are noteworthy for strategic decision making. Therefore, the following recommendations are made:

It is recommended that PNet should find more information about these well-qualified respondents, as they represent a lucrative portion of the market segment. Theoretically, the niche job-boards are the ones that PNet is likely to lose this lucrative market to, as they are characterised as communities for professional job seekers. On obtaining this information, PNet should consider two options, namely either to enter into partnership with the niche board-type of website or compete fiercely with them depending on which option will lead to higher profitability. Alternatively, PNet should consider ways to improve the dimensions that were perceived as less positive in order to increase the retention possibilities of these well-qualified job seekers.

It is also recommended that PNet should give more attention to the attraction of females to their website. This will enable the PNet website to be more in line with the requirements of gender equity, thus serving as a vehicle to reduce possible gender discrimination and stereotype.

Lastly, research on e-recruitment remains notably sparse, especially with regard to South Africa, and this presents countless research opportunities for both academics and practitioners. Findings and recommendations of this study may bring it to the attention of recruitment service providers or employers on how knowledge about their markets can improve their businesses' profitability.

\section{References}

Batini, C., Cappiello, C., Francalanci, C., \& Maurino, A. (2009). Methodologies for data quality assessment and improvement. ACM Computing Surveys, 41(3), 16.

Boritz, J. E. (2005). IS practitioners' views on core concepts of information integrity. International Journal of Accounting Information Systems, 6(4), 260-279.

Breaugh, J. A. (2008). Employee recruitment: Current knowledge and important areas for future research. Human Resource Management Review, 18(3), 103-118.

Casaló, L., Flavián, C., \& Guinalíu, M. (2008). The role of perceived usability, reputation, satisfaction and consumer familiarity on the website loyalty formation process. Computers in Human Behavior, 24(2), 325-345.

Celani, A., \& Singh, P. (2011). Signaling theory and applicant attraction outcomes. Personnel Review, 40(2), 222-238.

Churchill, G. A., \& lacobucci, D. (2005). Marketing research: methodological foundations. Thomson South-Western.

Constantinides, E. (2004). Influencing the online consumer's behavior: the web experience. Internet research, 14(2), 111-126.

Davis, F. D. (1989). Perceived usefulness, perceived ease of use, and user acceptance of information technology. MIS quarterly, 319340.

Egea, J. M.O., \& González, M. V. R. (2011). Explaining physicians' acceptance of EHCR systems: An extension of TAM with trust and risk factors. Computers in Human Behavior, 27(1), 319-332.

Hernández, B., Jiménez, J., \& Martín, M. J. (2009). Key website factors in e-business strategy. International Journal of Information Management, 29(5), 362-371.

Hsiao, C. H., \& Yang, C. (2011). The intellectual development of the technology acceptance model: a co-citation analysis. International Journal of Information Management, 31(2), 128-136.

Hu, C. Su, H., \& Chen, C. B. (2007). The effect of person-organisation fit feedback via recruitment web sites on applicant attraction. Journal of Computers in Human Behavior, 23, 2509-2523.

Kardes, F. R., Cline, T. W., \& Cronley, M. L. (2008). Consumer behavior: science and practice. South-Western Cengage Learning.

Kim, S., \& Stoel, L. (2004). Apparel retailers: website quality dimensions and satisfaction. Journal of Retailing and Consumer Services, $11(2), 109-117$

Kim, Y. J., Kishore, R., \& Sanders, G. L. (2005). From DQ to EQ: understanding data quality in the context of e-business systems. Communications of the ACM, 48(10), 75-81.

Kim, D. Y., Lehto, X. Y., \& Morrison, A. M. (2007). Gender differences in online travel information search: Implications for marketing communications on the internet. Tourism management, 28(2), 423-433. 
King, W. R., \& He, J. (2006). A meta-analysis of the technology acceptance model. Information \& Management, 43(6), 740-755.

Lang, S., Laumer, S., Maier, C., \& Eckhardt, A. (2011, May). Drivers, challenges and consequences of E-recruiting: a literature review. In Proceedings of the 49th SIGMIS annual conference on Computer personnel research (pp. 26-35). ACM.

Lee, I. (2005). The evolution of e-recruiting: a content analysis of Fortune 100 career web sites. Journal of Electronic Commerce in Organizations, 3(3), 57-68.

Lee, I. (2007). An architecture for a next-generation holistic e-recruiting system. Communications of the ACM, 50(7), 81-85.

Lee, I. (2011). Modeling the benefit of e-recruiting process integration. Decision Support Systems, 51(1), 230-239.

Lee, Y., \& Kozar, K. A. (2006). Investigating the effect of website quality on e-business success: an analytic hierarchy process (AHP) approach. Decision support systems, 42(3), 1383-1401.

Legris, P., Ingham, J., \& Collerette, P. (2003). Why do people use information technology? A critical review of the technology acceptance model. Information \& management, 40(3), 191-204.

Liaw, S. S. (2007). Computers and the Internet as a job assisted tool: based on the three-tier use model approach. Computers in Human Behavior, 23(1), 399-414.

Lin, P. C., \& Chou, Y. H. (2009). Perceived usefulness, ease of use, and usage of citation database interfaces: a replication. Electronic Library, The, 27(1), 31-42.

Liu, C., \& Chen, S. (2009). Prioritization of digital capital measures in recruiting website for the national armed forces. Expert Systems with Applications, 36(5), 9415-9421.

Livari, J. (2005). An empirical test of the DeLone-McLean model of information system success. ACM SIGMIS Database, 36(2), 8-27.

Lyons, B. D., \& Marler, J. H. (2011). Got image? Examining organizational image in web recruitment. Journal of managerial psychology, 26(1), 58-76.

Maurer, S. D., \& Liu, Y. (2007). Developing effective e-recruiting websites: Insights for managers from marketers. Business Horizons, 50(4), 305-314.

Norusis, M. J. (2009). PASW Statistics 18 statistical procedures companion. Prentice Hall.

Reynolds, D. H., \& Weiner, J. A. (2009). Online recruiting and selection: Innovations in talent acquisition. Wiley-Blackwell.

Schreurs, B. H., \& Syed, F. (2011). Battling the war for talent: an application in a military context. Career Development International, 16(1), 36-59.

Seddon, P., \& Kiew, M. Y. (2007). A partial test and development of DeLone and McLean's model of IS success. Australasian Journal of Information Systems, 4(1).

Shih, H. P. (2004). Extended technology acceptance model of Internet utilization behavior. Information \& Management, 41(6), 719-729.

Stone, D. L., Stone-Romero, E. F., \& Lukaszewski, K. (2006). Factors affecting the acceptance and effectiveness of electronic human resource systems. Human Resource Management Review, 16(2), 229-244.

Sylva, H., \& Mol, S. T. (2009). E-Recruitment: A study into applicant perceptions of an online application system. International Journal of Selection and Assessment, 17(3), 311-323.

Teo, H., Oha, L., Liu, C., \& Wei, K. (2003). An empirical study of the effects of interactivity on web user attitude. International Journal of Human-Computer Studies, 58(3), 281-305.

Thompson, L. F., Braddy, P. W., \& Wuensch, K. L. (2008). E-recruitment and the benefits of organizational web appeal. Computers in Human Behavior, 24(5), 2384-2398.

Tong, D. Y. K., \& Sivanand, C. N. (2005). E-recruitment service providers review: International and Malaysian. Employee relations, 27(1), 103-117.

Tong, D. Y. K. (2009). A study of e-recruitment technology adoption in Malaysia. Industrial Management \& Data Systems, 109(2), 281300.

Van Birgelen, M. J., Wetzels, M. G., \& Van Dolen, W. M. (2008). Effectiveness of corporate employment web sites: How content and form influence intentions to apply. International Journal of Manpower, 29(8), 731-751.

Welman, C., Kruger, F., \& Mitchell, B. (2005). Research methodology. Oxford University Press.

Williamson, I. O., Lepak, D. P., \& King, J. (2003). The effect of company recruitment web site orientation on individuals' perceptions of organizational attractiveness. Journal of Vocational Behavior, 63(2), 242-263.

Wixom, B. H., \& Todd, P. A. (2005). A theoretical integration of user satisfaction and technology acceptance. Information systems research, 16(1), 85-102.

Wolfswinkel, J., Furtmüller, E., \& Wilderom, C. (2010). Reflecting on e-recruiting research using grounded theory. European Conference on Information Systems, 18:1-12.

Yousafzai, S. Y., Foxall, G. R., \& Pallister, J. G. (2007). Technology acceptance: a meta-analysis of the TAM: Part 1. Journal of Modelling in Management, 2(3), 251-280.

Zusman, R. R., \& Landis, R. S. (2002). Applicant preferences for web-based versus traditional job postings. Computers in Human Behavior, 18(3), 285-296. 